\title{
Are thyroid functions affected in children diagnosed with COVID-19?
}

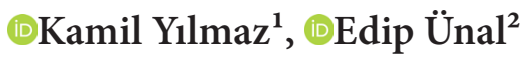 \\ ${ }^{1}$ Dicle University, Faculty of Medicine, Department of Pediatrics, Diyarbakır, Turkey \\ ${ }^{2}$ Dicle University, Faculty of Medicine, Department of Pediatric Endocrinology, Diyarbakır, Turkey
}

Cite this article as: Yllmaz K, Unal E. Are thyroid functions affected in children diagnosed with COVID-19?. J Health Sci Med 2021; 4(3): 257-261.

\begin{abstract}
Introduction: In December 2019, a novel type of coronavirus infection (SARS-CoV-2) emerged in China and started to spread rapidly. It is unclear whether the thyroid gland is affected in patients with COVID-19. We aimed to investigate the changes in thyroid function in pediatric patients with COVID-19.

Material and Method: This study enrolled 79 patients aged 0-18 years with confirmed COVID-19 and the control group consisted of 57 healthy children. All patients thyroid function tests and acute phase reactants were studied.

Results: The median age was 132 months in the patient group and 108 months in the control group. TSH level was lower in the COVID-19 patients compared to the controls although the difference did not statistical significance $(\mathrm{p}=0.051)$. Free T3 level was significantly lower in the patient group compared to the control group $(\mathrm{p}<0.001)$. All patients with COVID-19 had normal TSH levels and fT3 was lower in 7 (8.8\%) of 79 patients. Correlation analysis showed a negative correlation between fT3 level and CRP, procalcitonin levels. No significant correlation was found between disease severity and thyroid hormone levels.

Conclusion: as far as we know, our study is the first to evaluate thyroid functions in children with COVID-19. As in many other severe disease states, ESS may develop in COVID-19. It can be concluded that the pituitary-thyroid axis is not severely affected in pediatric patients COVID-19, especially in those with asymptomatic or mildly symptomatic disease. It should be remembered that the disease course may be more severe particularly in patients who develop ESS.
\end{abstract}

Keywords: COVID-19, euthyroid sick syndrome, fT3, thyroid

\section{INTRODUCTION}

In December 2019, a novel type of coronavirus infection (SARS-CoV-2) emerged in Wuhan City of China and started to spread rapidly. The virus has affected more than 200 countries in 6 continents worldwide and caused a global pandemic. Named as COVID-19 by World Health Organization (WHO), the disease has reportedly caused $65,257,767$ confirmed cases and $1,513,179$ deaths as of 5 December 2020, according to WHO data (1). The pathophysiology of COVID-19, which has a high contagiousness and mortality rate, has not been fully elucidated. It has been reported that many organs and systems including the respiratory, immune, gastrointestinal, circulatory, renal, and hematological systems are affected in patients with COVID-19 (2).

Euthyroid sick syndrome (ESS) is the name of a condition that refers to changes in thyroid function in the absence of a primary problem of the thyroid gland during acute disease states. The most typical changes include reduced plasma triiodothyronine (T3) level, low or normal plasma thyroxine (T4) level, and a normal or slightly reduced Thyroid-stimulating hormone (TSH) level (3). The euthyroid sick syndrome is a physiologic condition state that is resulted from fasting state in healthy individuals, malnutrition, infections, surgical procedures, myocardial iskemia and malignancy (4). Former studies have shown that particularly lower fT3 levels are correlated to disease severity and poor prognosis in critical diseases $(5,6)$. In addition, other studies have found that thyroid dysfunction develops in patients with severe acute respiratory syndrome caused by a different coronavirus strain (7-9). However, it is unclear whether the thyroid gland is affected in patients with COVID-19 caused by SARS-CoV-2, which currently causes a worldwide pandemic. The SARS$\mathrm{CoV}-2$ virus uses the angiotensin II converting enzyme (ACE-2), a carboxypeptidase, as a "receptor" to enter body 
cells. It has recently been reported that ACE-2 is highly expressed in the thyroid tissue (10). This suggests that the thyroid gland may be a potential target for a direct attack by COVID-19. There are very few studies evaluating the relationship between COVID-19 infection and thyroid function tests (11-14). All studies performed so far have been conducted in adults. As far as we know, no study in the literature has yet evaluated thyroid functions in children with COVID-19. Herein, we aimed to investigate the changes in thyroid function, euthyroid sick syndrome, and its relationship with acute phase reactants in pediatric patients with COVID-19.

\section{MATERIAL AND METHOD}

The study was conducted in compliance with the criteria of the Helsinki Declaration. It was approved by the Republic of Turkey Ministry of Health and Local Ethics Committee at Dicle University Faculty of Medicine (Date: 26.11.2020, Decision No: 358). Written informed consent was obtained from all participants who participated in this study.

This study enrolled 79 patients aged 0-18 years with confirmed COVID-19 who were admitted to Dicle University Faculty of Medicine Department of Pediatrics COVID-19 clinic between May 2020 and August 2020; the control group consisted of 57 healthy children. COVID-19 was diagnosed by the real-time reverse transcriptionpolymerase chain reaction (RT-PCR) method, which was studied from the nasopharyngeal swab samples. C-reactive protein (CRP), procalcitonin, ferritin, D-Dimer, and thyroid function tests were recorded from the medical records of the patients. In addition, the correlation between fT3 and acute phase reactants was tested.

The acute phase reactants and thyroid hormone levels were evaluated according to the reference values of the local laboratory. Levels that were above the upper reference limit were considered "high", and the ones below the lower reference limit were considered "low". The euthyroid sick syndrome was defined as a reduced serum T3 and/or T4 level without increased TSH secretion (3).

Patients who had suspected COVID-19 that was not confirmed by the RT-PCR method, history of thyroid disease, or suspected underlying hypothalamic or pituitary disease; patients who had missing laboratory parameters; and patients with comorbidities were excluded from the study. The control group consisted of age-and sex-matched completely healty children aged 0-18 years, who had no known thyroid disease or a chronic disorder.

The severity of the disease was classified as asymptomatic, mild, moderate, severe, and critical according to the clinical characteristics, laboratory results, and chest radiography findings.
Asymptomatic: Cases with a positive RT-PCR test without any clinical or radiological findings.

Mild: Cases with symptoms of upper respiratory tract infection, such as fever, fatigue, myalgia, cough, sore throat, nasal discharge, but a normal respiratory system examination.

Moderate: Cases with pneumonia with fever and cough but without dyspnea and hypoxemia, or cases with COVID-19 findings on chest CT scan without symptoms.

Severe: Cases with fever and cough in the early period who develop dyspnea and central cyanosis within a week (arterial oxygen saturation $<92 \%$ ).

Critical: Cases who rapidly develop acute respiratory distress or respiratory failure, and who tend to develop shock, encephalopathy, myocardial involvement, coagulation defects, and acute kidney injury.

\section{Statistical Analysis}

The study data were analyzed using the "Statistical Package for Social Sciences (SPSS) for Windows 22" software package. The continuous variables were presented as mean \pm standard deviation (SD) or median and interquartile range (IQR); the categorical variables were presented as number and percentage (\%). The normality of the study data was tested using the Shapiro Wilk test. Normally distributed variables were compared between the patient and control groups using Student's t-test. Correlation between numerical variables was tested with Pearson's Correlation Analysis. Mann Whitney-U test was used to compare non-normally distributed parameters. A p-value of $\leq 0.05$ was considered statistically significant for all statistical tests.

\section{RESULTS}

Forty-eight (60.8\%) of 79 patients and 38 (66.6\%) control subjects were male. The median age was 132 months (25th75th quartiles: $60-180$ months) in the patient group and 108 months (25th-75th quartiles: $92-130$ months) in the control group. There was no significant difference between the two groups in terms of sex distribution and median age $(\mathrm{p}=0.58, \mathrm{p}=0.10$, respectively). In the patient group, the median TSH level was $1.88 \mu \mathrm{IU} / \mathrm{mL}$ (25th-75th quartiles: $1.26-2.53 \mu \mathrm{IU} / \mathrm{mL}$ ); the mean fT4 level was $1.16 \pm 0.16 \mathrm{ng} /$ $\mathrm{dL}$, and the mean fT3 level was $3.58 \pm 0.61 \mathrm{pg} / \mathrm{mL}$. In the control group, the median TSH level was $2.30 \mu \mathrm{IU} / \mathrm{mL}$ (25th-75th quartiles: $1.79-2.93 \mu \mathrm{IU} / \mathrm{mL}$ ): the mean $\mathrm{fT} 4$ level was $1.14 \pm 0.12 \mathrm{ng} / \mathrm{dL}$, and the mean fT3 level was $4.38 \pm 0.38 \mathrm{pg} / \mathrm{mL}$. TSH level was lower in the COVID-19 patients compared to the controls although the difference did not reach statistical significance $(\mathrm{p}=0.051)$. fT3 level was significantly lower in the patient group compared to the control group $(\mathrm{p}<0.001)$. 
All patients with COVID-19 had normal TSH levels according to the reference range of the local laboratory. fT3 was lower in 7 (8.8\%) of 79 patients with COVID-19. Among those seven patients, two also had low fT4 levels, who were considered as having ESS. The laboratory and demographic characteristics of both groups were summarized in Table 1. Sixteen (20.2\%) patients had a higher CRP level than normal; 31 (39.9\%) patients had a higher procalcitonin level than normal, and $5(6.3 \%)$ patients had a higher ferritin level than normal. Five (71.4\%) of seven patients considered as having ESS had a high procalcitonin level, and four (51.1\%) had a high CRP level.

\section{Table 1. Comparison of demographic and laboratory}

characteristics between COVID-19 patient group and healty control subject group

\begin{tabular}{|c|c|c|c|}
\hline Parameters & $\begin{array}{c}\text { COVID-19 } \\
\text { patients }(n=70)\end{array}$ & $\begin{array}{c}\text { Healthy } \\
\text { controls } \\
(\mathrm{n}=57)\end{array}$ & $\mathbf{p}$ \\
\hline Age (month) & $132(60-180)^{\mathrm{a}}$ & $\begin{array}{c}108 \\
(92-130)^{\mathrm{a}}\end{array}$ & 0.10 \\
\hline Gender (M/F) & $48 / 31$ & $38 / 19$ & 0.58 \\
\hline $\begin{array}{l}\mathrm{TSH}(\mu \mathrm{IU} / \mathrm{mL}) \\
\text { (ref.: } 0.35-5.5)\end{array}$ & $\begin{array}{c}1.88 \\
(1.26-2.53)^{\mathrm{a}}\end{array}$ & $\begin{array}{c}2.30 \\
(1.79-2.93)^{\mathrm{a}}\end{array}$ & 0.051 \\
\hline $\begin{array}{l}\text { fT3 }(\mathrm{pg} / \mathrm{mL}) \\
(\text { ref.: } 2.3-4.2)\end{array}$ & $3.58 \pm 0.61^{b}$ & $4.38 \pm 0.38^{\mathrm{b}}$ & $<0.001$ \\
\hline $\begin{array}{l}\text { fT4 }(\mathrm{ng} / \mathrm{dL}), \\
\text { ( ref.: } 0.89-1.76)\end{array}$ & $1.16 \pm 0.16^{\mathrm{b}}$ & $1.14 \pm 0.12^{\mathrm{b}}$ & 0.53 \\
\hline $\begin{array}{l}\mathrm{CRP}(\mathrm{mg} / \mathrm{dL}) \\
\text { ref.: }(0.0-0.5)\end{array}$ & $\begin{array}{c}0.15 \\
(0.05-0.39)^{\mathrm{a}}\end{array}$ & - & - \\
\hline $\begin{array}{l}\text { Procalcitonin }(\mathrm{ng} / \mathrm{mL}) \text {, } \\
\text { ref.:(0.0-0.12) }\end{array}$ & $\begin{array}{c}0.05 \\
(0.01-0.15)^{\mathrm{a}}\end{array}$ & - & - \\
\hline $\begin{array}{l}\text { Ferritin levels }(\mathrm{ng} / \mathrm{ml}) \text {, } \\
\text { ref.: }(10-291)\end{array}$ & $\begin{array}{c}31.7 \\
(17.3-80.9)^{\mathrm{a}}\end{array}$ & - & - \\
\hline $\begin{array}{l}\text { D-dimer }(\mathrm{mg} / \mathrm{dL}) \\
\text { ref. : }(0.08-0.583)\end{array}$ & $\begin{array}{c}0.45 \\
(0.32-0.72)^{\mathrm{a}} \\
\end{array}$ & - & - \\
\hline
\end{tabular}

Pearson's correlation analysis showed a negative correlation between fT3 level and CRP, procalcitonin levels (respectively, $\mathrm{r}=-0.456, \mathrm{r}=-0.372, \mathrm{p}<0.001, \mathrm{p}=0.001$ ). Of all patients, $86.1 \%$ had asymptomatic or mild disease, and $13.9 \%$ had moderately severe disease whereas no patient had a severe or critical disease. Glucocorticoid was not used in the treatment of any patients. None of patients developed MIS-C. No significant correlation was found between disease severity and thyroid hormone levels (Table 2).

\begin{tabular}{|c|c|c|}
\hline Parameters & $\mathbf{r}$ & $\mathbf{p}$ \\
\hline CRP & -0.456 & $<0.001$ \\
\hline Procalcitonin & -0.372 & 0.001 \\
\hline Ferritine & -0.197 & 0.082 \\
\hline D-dimer & 0.203 & 0.73 \\
\hline TSH & 0.117 & 0.305 \\
\hline $\mathrm{fT} 4$ & 0.360 & 0.001 \\
\hline Disease severity & -0.188 & 0.098 \\
\hline
\end{tabular}

\section{DISCUSSION}

In the present study, we demonstrated that fT3 level was significantly lower in the hospitalized COVID-19 patients compared to the controls; we also showed that there was a negative correlation between fT3 level and inflammatory parameters, i.e. procalcitonin and CRP. ESS was detected in $8.8 \%$ of the COVID-19 patients but none of them had a low TSH level.

Non-thyroid disease syndrome or ESS is a condition characterized by a reduced T3 level in persons with a normal thyroid function. It is particularly found in critically ill patients or those with severe malnutrition. Previous studies have shown that ESS is associated with disease severity and poor prognosis $(5,6)$. It has been shown that reduced fT3 levels were strongly predictive of worse disease course, particularly in critically ill patients who are admitted to the intensive care unit $(15,16)$. It is still unclear whether the thyroid gland is affected by SARS-CoV-2. Thyroid dysfunction has been reported in patients with the severe acute respiratory syndrome (SARS) caused by a different coronavirus strain. A prior study showed follicular cell damage in the thyroid gland of SARS patients, resulting in reduced T3 and T4 levels. That study also suggested that thyroid follicular damage may partly occur due to apoptosis (7). Another study showed significantly lower TT3, TT4, and TSH levels in patients with SARS compared to controls, both in the progressive and recovery phases of the disease (8). Wei et al. (9) studied the cells in the adenohypophysis during the autopsies of 5 patients with SARS; they detected a reduced number and staining intensity of TSH-positive cells in the pituitary glands of the patients. This was interpreted that SARS disease causes alterations in TSH secreting cells in the pituitary gland. Abnormal thyroid function tests were shown in SARS-CoV infection in all of the above-mentioned studies (7-9). There are, however, very few studies evaluating the relationship between the SARS-CoV-2 infection, which currently causes a pandemic, and thyroid function tests (11-14). It is unclear whether the changes in thyroid function tests detected by those studies are simply due to ESS or direct involvement of the thyroid or pituitary gland. A recent study compared the thyroid function tests of patients with COVID-19 and non-COVID-19 pneumonia; it concluded that TSH and T3 levels were lower in patients with COVID-19. The same study also detected reduced TSH levels in spite of normal levels of other thyroid hormones in $34 \%$ of the patients. The authors stressed that this finding may not be explained solely by ESS, but also by a specific effect of COVID-19 on TSH-secreting cells. However, the authors emphasized that $62 \%$ of their patients received glucocorticoid treatment, which may have suppressed the pituitary-thyroid axis (12). In a 
study by Wang et al. (11), 61.9\% (52/84) of 84 COVID-19 patients developed thyroid dysfunction. They found that COVID-19 patients had lower TT3 levels compared to healthy controls but comparable TT3 levels with patients having non-COVID-19 pneumonia. However, they detected lower TSH levels in the COVID-19 patients, both compared to healthy controls and patients with non-COVID-19 pneumonia. That study did not provide specific information about glucocorticoid use. Another study comprising 100 adult patients with COVID-19 revealed that fT3 levels were lower in patients with the severe disease than patients without severe disease; deceased patients had the lowest fT3 levels. The reduction in free T3 was found to be correlated to all-cause mortality. That study also reported lower fT3 levels in $39.4 \%$ of severe and critical patients but only in $5.9 \%$ of patients with the non-severe disease. Furthermore, reduced TSH levels were not observed in any of the non-severe cases whereas it was present in $10.6 \%$ of severe or critically ill patients. The authors reported that very few patients received steroid therapy; thus, they argued that their results were free of the effects of glucocorticoid therapy (14). Our study results concerning the thyroid function tests show similarities with those reported by Gou et al. (14). Among our patients, $86.1 \%$ were asymptomatic; $13.9 \%$ had moderately severe disease, and none of them had a severe or critical disease. Therefore, no patient without the severe disease had a reduced TSH level, as Gou et al. (14) reported. In addition, the prevalence of reduced fT3 levels was found $8.8 \%$ while Gou et al. (14) reported reduced fT3 levels in 5.9\% of non-severe cases.

Our study revealed a lower rate of thyroid dysfunction and ESS compared to studies on adults (11-13). This may be related to a milder COVID-19 course in children, a markedly lower incidence of inflammatory processes leading to cytokine storm, an extremely lower rate of glucocorticoid use, and perhaps a lower number of ACE2 receptors in children compared to adults. Studies in adult populations have reported that thyroid dysfunction was associated with the severity of COVID-19 disease $(11,12,14)$; the levels of inflammatory parameters such as $\mathrm{CRP}$ and procalcitonin were higher in patients developing thyroid dysfunction $(11,13)$, and fT3 level showed a negative correlation to CRP (14). There was a negative correlation between fT3 and CRP, procalcitonin. A gradual reduction in $\mathrm{fT} 3$ level as inflammatory response deepened in COVID-19 infection supported the findings of previous studies.

The limitations of our study include its retrospective design and a low number of patients. In addition, no patient with severe or critical disease was enrolled. Thyroid functions could not be controlled because they did not come for control after the disease.

\section{CONCLUSION}

As far as we know, our study is the first to evaluate thyroid functions in children with COVID-19. As in many other severe disease states, ESS may develop in COVID-19. It can be concluded that the pituitarythyroid axis is not severely affected in pediatric patients COVID-19, especially in those with asymptomatic or mildly symptomatic disease. However, in order to reach a clear conclusion on this subject, there is a need for studies with a larger sample size that would involve patients with severe disease. It should be remembered that the disease course may be more severe particularly in patients who develop ESS.

\section{ETHICAL DECLARATIONS}

Ethics Committee Approval: It was approved by the Republic of Turkey Ministry of Health and Local Ethics Committee at Dicle University Faculty of Medicine (Date: 26.11.2020, No: 358).

Informed Consent: Written informed consent was obtained from all participants who participated in this study.

Referee Evaluation Process: Externally peer-reviewed. Conflict of Interest Statement: The authors have no conflicts of interest to declare.

Financial Disclosure: The authors declared that this study has received no financial support.

Author Contributions: All of the authors declare that they have all participated in the design, execution, and analysis of the paper, and that they have approved the final version.

Acknowledgements: We also thanks Velat Şen for his support.

Note: This article was previously the "Milli Pediatri Derneği Cocuk Hekiminin bir Günü” presented as oral presentations at the meeting called in 15.10.2020.

\section{REFERENCES}

1. World Health Organization. Available from: https: //covid19. who.int/.

2. Li Y, He F, Zhou N, et al. Organ function support in patients with coronavirus disease 2019: Tongji experience. Front Med 2020; 14 : 232-48. doi: 10.1007/s11684-020-0774-9

3. Boelen A, Kwakkel J, Fliers E. Beyond low plasma T3: local thyroid hormone metabolism during inflammation and infection. Endocr Rev 2011; 32: 670-93.

4. Lee S, Farwell AP. Euthyroid Sick Syndrome. Compr Physiol 2016; 6: 1071-80.

5. Scoscia E, Baglioni S, Eslami A, Iervasi G, Monti S, Todisco T. Low triiodothyronine (T3) state: a predictor of outcome in respiratory failure? Results of a clinical pilot study. Eur J Endocrinol 2004; 151: 557-60. 
6. Bertoli A, Valentini A, Cianfarani MA, Gasbarra E, Tarantino U, Federici M. Low FT3: a possible marker of frailty in the elderly. Clin Interv Aging 2017; 12: 335-41.

7. Wei L, Sun S, Xu CH, et al. Pathology of the thyroid in severe acute respiratory syndrome. Hum Pathol 2007; 38: 95-102.

8. Wang W, Ye YX, Yao H, Sun LQ, Wang AS, Wang ZY. Evaluation and observation of serum thyroid hormone and parathyroid hormone in patients with severe acute respiratory syndrome. J Chin Antituberculous Assoc 2003; 25: 232-4.

9. Wei L, Sun S, Zhang J, et al. Endocrine cells of the adenohypophysis in severe acute respiratory syndrome (SARS). Biochem Cell Biol 2010; 88: 723-30.

10.Li MY, Li L, Zhang Y, Wang XS. Expression of the SARS-CoV-2 cell receptor gene ACE2 in a wide variety of human tissues. Infect Dis Poverty 2020; 9: 45. doi: 10.1186/s40249-020-00662-x

11. Wang W, Su X, Ding Y, et al. Thyroid function abnormalities in COVID-19 patients. MedRXiv 2020 Jan 1. doi: $10.1101 / 2020.06 .15 .20130807$

12. Chen M, Zhou W, Xu W. Thyroid Function Analysis in 50 Patients with COVID-19: A Retrospective Study. Thyroid 2021; 31: 8-11. doi: $10.1089 /$ thy.2020.0363

13.Zou R, Wu C, Zhang S, et al. Euthyroid Sick Syndrome in Patients With COVID-19. Front Endocrinol (Lausanne) 2020; 11: 566439. doi: $10.3389 /$ fendo.2020.566439

14. Gao W, Guo W, Guo Y, et al. Thyroid hormone concentrations in severely or critically ill patients with COVID-19. J Endocrinol Invest 2020; 1-10. doi: 10.1007/s40618-020-01460-w

15. Rothberger GD, Valestra PK, Knight K, Desai AK, Calixte R, Shapiro LE. Low free T3 is associated with worse outcomes in patients in the ICU requiring invasive mechanical ventilation. J Intensive Care Med 2019; 885066619890822. doi: $10.1177 / 0885066619890822$

16. Bello G, Pennisi MA, Montini L, et al. Nonthyroidal illness syndrome and prolonged mechanical ventilation in patients admitted to the ICU. Chest 2009; 135: 1448-54. 